\title{
RELAÇÕES ESTÉTICAS E UMA ÉTICA PARA UM MUNDO VIVO
}

\author{
Janaina Rocha Furtado ${ }^{\star}$
}

\begin{abstract}
Resumo
Este artigo trata das relações estéticas e sua relevância para criar novas formas de produção de conhecimentos, as quais sejam capazes de preservar a vida. Entende-se que a partir de relações mais sensiveis com tudo o que vive é possivel construir outra ética de existência, bem como outras práticas em ciência e em psicologia. A partir de vários autores discute-se sobre as estéticas cotidianas e as possibilidades de ampliar as percepções sobre o mundo. A critica às práticas científicas modernas faz-se pertinente, neste contexto, enquanto viabiliza a discussão dos moldes de pensamento que perpetuam e fundamentam um projeto de sociedade que não se sustenta na manutenção da vida.
\end{abstract}

Palavras-chave: relações estéticas; natureza; sensibilidade; ciência; psicologia.

\section{THE ESTHETIC RELATIONS AND AN ETHIC FOR A LIVING WORLD}

\begin{abstract}
This article discusses the aesthetic relations and its relevance to the new forms of knowledge production, which are capable of preserving life. It is understood that from the most sensitive relationships with all that lives it is possible to construct an ethic of existence, as well as other practices in science and psychology starting with several authors discusses more about the everyday aesthetic possibilities and broadens perceptions about the world. The criticism of modern scientific practices it is relevant in this context, while allowing the discussion of thought patterns that perpetuate and justify a project of society that cannot be sustained in the maintenance of life.
\end{abstract}

Keywords: aesthetic relations; nature; sensibility; science; psychology.

\footnotetext{
^ Psicóloga. Mestre em Psicologia Social pela Universidade Federal de Santa Catarina. Endereço: Departamento de Psicologia - Centro de Filosofia e Ciências Humanas. Universidade Federal de Santa Catarina - UFSC. Campus Universitário - Trindade - Florianópolis - Santa Catarina Brasil. CEP 88.040-970.

E-mail: janarf1@yahoo.com.br
} 
Avultam no contexto científico contemporâneo as críticas aos pressupostos paradigmáticos da ciência clássica ou dita moderna, difundindo-se por diversas áreas do conhecimento e campos de investigação (SANTOS, B., 2003, 2004; FOUCAULT, 1972; JAPIASSU, 1983; CAPRA, 2001; MORIN, 2000; MAFFESOLI, 1998). Críticas no que se refere, especialmente, à lógica determinista e funcionalista que, segundo os autores, possibilitou a vigência de concepções mecânicas sobre mundo e seres humanos.

Segundo Santos, B. (2003, p. 28) para a ciência moderna de base cartesiana "conhecer significa dividir e classificar para depois poder determinar relações sistemáticas entre o que se separou". A pretensa dominação da natureza compreendida como extensão eterna e reversível resultaria de pretendidas leis universais que viabilizariam, por sua vez, a perspectiva do seu controle. Com este escopo e a partir de seus princípios epistemológicos próprios, a ciência moderna construiu fundamentos teórico-metodológicos para promover a percepção de um mundo estático, sólido, linear, causal e um modelo determinado de sociedade.

Bergson (2005) nos coloca, entretanto, que nenhuma das categorias de nosso pensamento se aplica de forma exata às coisas da vida. A vida excede! Não nos é permitido medi-la, controlá-la ou dominá-la. Sendo assim, cabe-nos perguntar: será que temos conseguido produzir conhecimentos que nos possibilitam compreender as complexidades inerentes à organização da vida? Será lícito perguntar sobre os compromissos éticos da ciência com o que vive? Que sociedade é projetada pelos conhecimentos produzidos e que práticas sociais decorrem dos mesmos? Quais outras formas de produzir conhecimento são possíveis e a partir de que pressupostos?

Maffesoli (1998) acredita que estamos traçando novos caminhos, vivendo uma reviravolta no planeta e um momento atual de reencantamento do mundo, despertando-nos para uma razão mais sensível. Movimentos de analisar, fragmentar, dividir transformaram-se em movimentos de abranger, compreender, contemplar. Estariam as certezas tornando-se incertezas? Ordens em desordens? Previsibilidades em imprevisibilidades?

Ao entendermos que "em vão empurramos o vivo para dentro de tal e tal de nossos quadros. Todos os quadros estouram. São estreitos demais, sobretudo rígidos demais, para aquilo que gostaríamos de colocar neles" (BERGSON, 2005, p. XX), pretendemos dialogar sobre as relações sensíveis, sendo essas outras relações possíveis entre seres humanos com o mundo vivo.

Nosso modo de produzir ciência e pensar o mundo reflete e constrói os modos como vivemos o mundo. Segundo Bergson (2005), vimos utilizando demasiadamente o método intelectual que opera dos conceitos para a realidade, buscando encaixá-la, quase sempre, nas molduras de um quadro ou engavetá-la no espaço igualmente confortável do já concebido.

Formas de pensar o mundo nos moldes da ciência clássica mais que sentilo ou intuí-lo, como aponta o autor, há muito tem garantido o entendimento de que estamos cindidos da natureza e das coisas. Alheios às relações que produ- 
zem um modelo de sociedade desigual e um planeta desgastado. Talvez precisemos questionar como pensar o mundo sem deixar de considerar o que é sentido e experimentado.

Neste sentido, a tessitura aqui pretendida refere-se à composição da dimensão estética na/da vida, possibilitando outras percepções e outras práticas, o que pode trazer em sua envergadura uma discussão ética fundamental: uma ética da vida para uma ciência da vida.

\section{RELAÇÕES ESTÉTICAS: INTENÇÕES PARA UMA ÉTICA DA EXISTÊNCIA}

A palavra estética deriva da denominação grega aesthesis e significa faculdade de sentir, compreensão dos sentidos, percepção totalizante. Usualmente estética é relacionada com arte e beleza, mas entendemos que esta relação configura uma restrição de sentido da palavra e das possibilidades de experimentação estética de modo geral.

Relações estéticas se referem a relações nas quais os objetos são apreendidos muito mais por sua forma e significado que por sua função (VÀSQUEZ, 1999). Relações que se fundamentam e se fundam na sensibilidade, na imaginação e emoções, pelas quais os objetos da experimentação estética são abrangidos simbolicamente.

Para Barrios (1999), é necessário considerar a experiência estética como uma experiência vital e sensível, em que se perde a distância entre imaginação e realidade e em que se aceita um mundo do sentido por via lúdica. "Es dicer, donde la experiencia estética no se encuentra separada de la existência de los indivíduos y es um acceso sensible e imaginario al mundo, a la possibilidade de la ficcionalidad misma de la realidad" (BARRIOS, 1999, p. 69-70).

As relações estéticas reivindicam, portanto, posturas outras nas quais o ser humano encontra-se afetado pelo mundo e suas percepções compõem ritmos variados entre os objetos e os entornos, formas e significados, estético e extra-estético. A relação estética não é uniforme, unitária, não está nem no sujeito e nem no objeto, mas na relação entre sujeitos e objetos (VÁSQUEZ, 1999). De modo que relações estéticas são singulares, implicam sujeitos e suas histórias particulares, imaginários plurais e jeitos próprios de sentir e conviver com o que nos circunda.

Pode-se dizer que o olhar estético é, portanto, aquele que olha para fora e ao mesmo tempo para dentro, desfocando-se das necessidades imediatistas e permitindo-se apenas experimentar. O olhar estético é aquele que desliza e encontra brechas nos significados comumente partilhados em determinado contexto social. Aquele olhar estrangeiro dito por Peixoto (2003), produzido por um caminhar lento, que contempla, estranha e se surpreende. 
Bakhtin (2003) e Vygostky (1995), à sua época, acreditavam que por meio da educação estética pode-se vislumbrar a construção de um Homem Novo. De acordo com Bakhtin (2003, p. 205), "o ato estético engendra a existência num novo plano de valores do mundo; nasce um novo homem e um novo contexto de valores - um novo plano do pensamento do homem sobre o mundo".

Vygostky (2001), por sua vez, defendeu a importância das relações sensíveis para a emergência de outro sujeito ou, diríamos nós, outras subjetividades. De um ser humano que no encontro com tudo que existe, com os produtos da atividade humana, movimentos, gestos, cores, cheiros, pode estabelecer um contato emocionado. Propunha ele que a educação estética fizesse parte da educação formal para que se aprendesse desde cedo a olhar o mundo a partir dessas novas ferramentas pessoais. Não para que as crianças viessem a entender a história da arte e citar a qual período pertence tal e qual pintor, mas para que aprendessem a olhar. Em com novo olhar despertassem o sentir e se voltassem para si mesmas, para suas sensações e emoções, para a abertura que as relações estéticas podem vir a produzir, qualitativamente, na vida e nas relações que fundamos com o mundo.

Insere-se, assim, a perspectiva de que a realidade é apreendia e significada não apenas pela via racional, mas também por meio das relações sensíveis experimentadas, vividas. No entanto, o enfoque sobre a razão na ciência, e a priorização das relações prático-utilitárias no cotidiano, possibilitou a configuração de uma subjetividade contemporânea que pouco qualifica ou se debruça sobre estas outras relações possíveis entre as pessoas e delas com a realidade.

\section{É POSSÍVEL FAZER PRODUZIR CONHECIMENTO A PARTIR DESTAS RELAÇÕES ESTÉTICAS?}

Há algum tempo vimos discutindo as relações entre ciência e processos de criação, ciência e estética. Nosso entendimento é que no processo de pesquisar implicam-se olhares outros para o supostamente conhecido, o que se constitui como processo de criação da própria pesquisa e do pesquisador no contínuo da sua atividade. Além de conhecimento e técnica, as relações estéticas, conquanto possibilitem a apropriação da realidade por meio do sensível, fundamentam processos de criação diversos. Sensibilidade como mediação para olhar, admirar e problematizar a realidade (ZANELLA; SAIS, 2008).

Coelho (1998/1999) afirma que Bergson distingue duas formas profundamente diferentes, porém complementares, de conhecer uma coisa: o conhecimento intelectual, que é relativo, espacializado, estático e por conceitos, envolvendo uma postura de cisão entre o sujeito do conhecimento e o objeto a ser conhecido; e o conhecimento intuitivo que consiste na coincidência com o particular, com o que não é traduzível por conceitos, fundando-se na ampliação do campo perceptivo.

[...] a intuição em Bergson não é apenas um método racional e preciso da filosofia, mas também uma faculdade irracional de conhecimento. Parece-nos que esses dois aspectos não são excludentes, mas ainda, que o primeiro é incompreensível sem o segundo (COELHO, 1998/1999, p. 152). 
Enquanto o método intelectual se forja na linguagem verbal, no espaço da palavra, no já conhecido, o método intuitivo seria aquele desenvolvido pelos artistas e também pelos filósofos que, desapegados das exigências do agir e do viver, conseguem uma percepção mais completa da realidade. Esta intuição bergsoniana corresponde muito intimamente ao que queremos trazer acerca das relações estéticas, enquanto percepção mais totalizante, e sua relevância para a construção de uma ética da vida.

Desta forma, não se trata de cindir razões e emoções, optando por uma ou outra, ou mesmo encontrar uma unidade indissolúvel entre estas instâncias, uma vez que também o conhecimento e a cognição se constituem no âmbito das relações sensíveis. Trata-se de promulgar subjetividades que se viabilizem pela via estética e considerar estas dimensões no campo da produção do conhecimento, pois "assim como falham as palavras quando querem exprimir qualquer pensamento, assim falham os pensamentos quando querem exprimir qualquer realidade" (PESSOA, 2008, p. 115).

Além das palavras, imagens e sensações configuram a incomensurabilidade entre o intelectual e o intuitivo, revelando-se em modos próprios de perceber a realidade. Por meio dos discursos e das diferentes linguagens é possível descartar o que está pronto, as certezas provisórias, construindo novas formas de pensar e sentir. O universo das imagens condensa os sentimentos, os sentidos, aquilo que não cabe nas palavras ou, muitas vezes, numa narrativa cronológica ou linear do pensamento. Como viabilizar isso no fazer científico? Como possibilitar que estas experiências sejam priorizadas no cotidiano? Eis um desafio!

É preciso aderir a novas práxis e possibilitar a produção de saberes a partir das experiências vividas na sua complexidade própria, sem tencionar traduzilos apenas por uma perspectiva funcional e utilitária. A utilização de diferentes linguagens parece ser uma saída, a fotografia, as filmagens, a poesia estão sendo apresentadas como meios para a expressão plural de realidades que são também multifacetadas, dialógicas e constituídas na diversidade dos olhares.

\section{Estética Cotidiana: RePercussões (IN)SEnSíveis}

Ao trazer a reflexão para as relações estéticas não estamos dizendo que impera uma insensibilidade geral e que a ciência moderna tenha desconsiderado de todo a faculdade do sentir e emocionar-se. Chama-nos a atenção, todavia, que tipo de sensibilidades temos valorizado em nossa sociedade e como vemos isso atrelado a uma concepção de ser humano, de natureza e de vida, produzida em diversos âmbitos sociais, onde a cisão parece ser a prerrogativa. Spinoza (1979) nos fala sobre os prazeres fáceis e os prazeres difíceis. Enquanto o primeiro provoca pouca potência de ação e diríamos de afetação com a realidade; o segundo, pelo contrário, possibilita o encontro de potências e a condição de transformação significativa de um sujeito em relação. 
Que sensibilidade é cultivada pelos doces ou fast food cujos sabores e excesso de sal e açúcares exacerbam o paladar até o último suspiro, não permitindo que sintamos a sutileza do sabor? Ao assistir "enlatados" americanos ou as novelas brasileiras nas quais as emoções são tratadas tão dramaticamente que perdem a força de conduzir a diversidade ou contradição de sensações? Que (in) sensibilidades nós temos produzido? Obviamente, não queremos hierarquizar ou valorar as relações estéticas a partir da produção cultural dos diferentes contextos sociais. Não nos cabe dizer o que é bom ou ruim e o que deve ser difundido ou não. Cabe-nos refletir sobre o quanto possibilitamos ou não subjetividades sensíveis à diversidade da vida, o modo como agenciamos os modos de olhar, perceber, sentir, pensar e viver.

Bachelard (2008) coloca que uma simples imagem não deixa de ter uma grande repercussão psíquica. Como, então, temos alimentado nosso imaginário? Por um lado, os prazeres fáceis fundam certa artificialidade subjetiva, ou seja, cunham formas mecanizadas e previsíveis de apropriação e significação da realidade e, assim, a configuração de uma determinada subjetividade e de determinados modos de viver. Por outro, não deixam de deixar seus vestígios no imaginário coletivo e tampouco na experiência singular de cada um de nós, tornando-se singularizadas e, portanto, operando nos nossos desejos e vontades.

Parece-nos, sim, que temos investido e consumido sensibilidades que estão a serviço de outros interesses. No mundo dos fetichismos visuais, das mercadorias, dos corpos-passagens, dos objetos-orgânicos, o êxtase visual foi explorado ao extremo, assim como exploramos, por outras vias, a desconexão da razão e da intuição. Compreendemos que se tratam dos diferentes caminhos, processos e produtos que resultam da emergência de uma dada concepção de ser humano, construída pouco a pouco com a Modernidade.

Às vezes é justamente no excesso do sentir, no extasiamento do sentido, que estamos viabilizando certas insensibilidades, anestesiamentos. Excesso, profusão e intensidade de informação que favorecem o aparelhamento e agenciamento do sentir. Por isso, o olhar/sentir estrangeiro, aquele se delonga, que observa e se observa no detalhe, na sutileza, na marca da diferença e exploram os demais sentidos que frequentemente esquecemos de considerar, tais como: sentido da imensidade espacial; sentido da profundidade; sentido da proporção; sentido do movimento; sentido do orgânico, dentre outros (CHARDIN, 2008), é capaz de provocar uma outra subjetividade e, também, outros saberes.

\section{OlHar Sensível da ALMA: PERCEPÇões ORgÂNiCAS de UM MUNDO VIVO}

Bergson $(2005,2005$, p. 18), ao refletir sobre uma ciência mecanicista que se faz na previsibilidade e reversibilidade dos movimentos orgânicos, afirma que a mesma esquece que "por toda parte onde algo vive, há, aberto em algum lugar, um registro no qual o tempo se inscreve". Nada na vida se repete exatamente como foi, pois no momento seguinte já somos outros de nós mesmos. Bergson (2005) nos im- 
pele a conjecturar que na aparente repetição também se encontra a duração, o tempo-espaço onde a vida cria algo a cada instante. De modo que sempre é a primeira vez, sempre é a única e sempre é irreversível, e o tempo duração dos nossos afetos.

Práticas científicas que almejam desbravar a natureza para delinear as leis deterministas de seu funcionamento fazem crer que olhamos o mundo tal qual ele é, ou seja, estável, sólido, dado, que está separado do ser humano e disponível para quem ousar descobri-lo, um mundo em espera. Assim, esta forma de fazer ciência não considera que o pesquisador é também aquele que se inscreve numa duração e numa relação que não se repete para o outro da mesma maneira. Nós selecionamos o que vemos, o que queremos ver e isso faz parte da nossa condição de existência, seja no cotidiano, seja na pesquisa. Neste sentido, a descrição de um método de pesquisa não devia se limitar a uma narrativa dura e impessoal acerca dos sujeitos, procedimentos e método de análise. Há um tempo e olhares pesquisador-pesquisado que se entregam e entrelaçam aí, há sentidos e sentimentos que se tecem na vida e, portanto, devem também se entretecer na escrita, na análise, na descrição da experiência de pesquisar, criar e se recriar enquanto pesquisador.

Para tanto, é necessário considerar que o olhar do pesquisador também cria e interfere na realidade a ser pesquisada. Gestaltistas como Wertheimer, Koffka e Kohler, entre outros cientistas há muito tem evidenciado como nosso cérebro encontra padrões, esquadrinha categorias e, após configurar o campo visual com rapidez inigualável, nos apresenta um mundo construído a partir de nossos próprios sentidos e percepções anteriores.

Maturana e Varella em seu livro A árvore do conhecimento (2001) enfatizam, por sua vez, que durante muito tempo se pensou que a percepção das cores num espectro de luz estava direta e estritamente relacionada ao comprimento de onda da luz. Assim, o mesmo comprimento deveria ser percebido como sendo referente à mesma cor por seres vivos de estruturas cognitivas semelhantes, como os seres humanos. Contudo, pesquisas demonstraram que o mesmo comprimento de luz era percebido como sendo de cores diferentes e variações em tonalidades da mesma cor. Concluiu-se que a percepção das cores dependia mais da estrutura do estado interior do organismo, ou seja, do modo como este organismo se organizou a partir das suas experiências anteriores, que da frequência de onda da luz irradiada. Assim sendo, não há uma realidade per si, percebida e acessada igualmente por pessoas diferentes, mas realidades que são construídas na relação entre sujeitos e objetos.

Se essas considerações podem ser feitas em relação à percepção das cores, quiçá a outros processos perceptivos, levando a debates acerca da relação entre ser humano e mundo, na construção da sua própria realidade. Esta mesma realidade que participa da constituição de seres humanos e suas sensibilidades. Por um lado, nós criamos, até certo ponto, o que vemos, participando ativamente do que vemos com o que somos. Por outro, temos usado categorias, conceitos e padrões para compreender estas implicações da existência. Ter clareza das 
interconexões que constituem a relação do ser humano no mundo requer, indubitavelmente, a criação de outras formas de pensar, compreender, perceber e de investigar estas mesmas relações.

Neste sentido, ao mesmo tempo em que forjamos uma aparente divisão do seres humanos do restante do mundo e forjamos também sensibilidades a favor de interesses outros como dizíamos antes, as capacidades e potencialidades de mudança estão disponíveis e podem ser criadas. Assim como criamos um universo de sensibilidades fáceis e insensibilidades cotidianas, assim podemos fazer o inverso, assim fazemos o inverso muitas vezes. Há de se perguntar, portanto: como perceber o mundo a partir de outras configurações? Como podemos modificar os parâmetros e padrões, inverter as categorias, ou melhor, desfazermo-nos delas?

Criar espaços para a educação estética, para sensibilidade do olhar, para a percepção da vida e seus mo(vi)mentos, para intuição da realidade, talvez possibilite, por fim, que nós possamos aprender a dar olhos aos nossos corações e não apenas à razão. Fundamentalmente, para que possamos nos ver integrados a um mundo vivo, que se organiza e se auto-regula independentemente de um sujeito que o observa. Isso quer dizer que nós construímos a realidade, mas esta realidade também se constitui para além da nossa presença.

Um dos questionamentos que nos inquieta se refere a compreender que o mundo é percebido e ao ser percebido por nós ele se constitui e nos constitui, contudo, a organização do que vive no mundo não depende necessariamente da nossa existência. Seria por demais antropocentrismo acreditar que tudo o que vive depende de nós. Talvez a crença demasiada nisto tenha favorecido a ideia de que o mundo nos pertence e que, por isso, podemos controlá-lo e usá-lo a nosso bel prazer.

\section{Mosaicos E Fractais: vida, homem e natureza}

Se as relações estéticas podem promover a construção contínua da dimensão do sensível na vida e na pesquisa, podem favorecer também a constituição de outra ética, uma ética da vida. O que se potencializa quando entendemos que as relações estéticas podem nos fazer compreender o quanto somos uma espécie dentre outras vivas num mundo vivo. Somos mais que parte da natureza, somos natureza.

Assim como a ciência moderna possibilitou práticas sociais de expurgação da alma e da subjetividade, estipulação de concepções e percepções de cisão entre sujeito e objeto, mente e corpo, assim também os preceitos cartesianos e o antropocentrismo Iluminista provocaram a cisão entre ser humano e natureza, ambiente e natureza (SANTOS, B., 2003).

A natureza passou a ser quase um estorvo no caminho do progresso humanitário, por isso sabe-se que:

[...] a história do homem sobre a Terra é uma história de rutura progressiva entre o homem e o entorno. Esse processo se acelera quando, praticamente ao mesmo tempo, o homem se 
descobre como indivíduo e inicia a mecanização do Planeta, armando-se de novos instrumentos para tentar dominá-lo (SANTOS, M., 1992, p. 97).

O anseio pelo controle da natureza por meio das explicações causais de seus processos dinâmicos, e da exploração de seus benefícios, promoveram a criação de tecnologias que exibimos como nosso atual modelo de vida. Entendo-nos separado dela, superior a ela seja pela escala evolutiva ou espiritual (SALATINO, 2001), permitimo-nos, desse modo, destruí-la. Assim feito, tendo desmatado o verde e criado cidades sem árvores, entendemos que estar próximo à natureza tem hoje a característica de melhorar nossa qualidade de vida. Contraditoriamente, ainda não modificamos o modelo confortável de viver já constituído, porque manter nosso estilo de vida e preservar a natureza são, por si só, práticas incompatíveis.

É preciso refletir, portanto, com que finalidade se aposta ainda em um projeto de sociedade que não considera essas dimensões, se este mesmo projeto viabiliza a extinção das condições que mantém nossa existência e as condições que garantem a nossa qualidade de vida, tornando-a melhor e mais saudável. Além disso, em quais pressupostos nos embasamos para acharmo-nos no direito e no dever de modificar o meio ambiente e as condições para a existência de muitos outros seres vivos ou mesmo de destruí-los?

Aprendemos, anteriormente, a considerar que somos uma parte importante e que a natureza é outra parte, além nós, não tão relevante. De fato, muitos de nós se concebem como seres superiores, sujeitos de direitos sobre um mundo natural a seu serviço.

Esse conflito crônico entre ser humano e natureza fundamenta, como sentidos pouco a pouco cristalizados em nossa cultura, as percepções sobre ela e as (in)sensibilidades no que se refere a nossa relação com ela. Não se trata, contudo, de avaliarmos as múltiplas interações entre partes e de somá-las, mas de aprendermos a observar as composições harmônicas e desarmônicas múltiplas em que cada parte é em si um universo complexo em uma realidade indivisível. São como fractais. Cada um de nós é parte e é todo.

Fractais são, neste sentido, figuras orgânicas cujas partes se repetem iterativamente, em escala decrescente de crescimento, sendo que estas partes apresentam-se como que frações dele mesmo, quase idênticas. Os fractais se referem a padrões organizados de comportamento dentro de sistemas caóticos, aleatórios (MANDELBROT, 2001). De acordo com Mandelbrot (2001), criador dos fractais na década de 1950, estes mesmos padrões organizados podem ser encontrados na natureza, nas formas dos seres vivos se organizarem.

Isso nos leva à reflexão que fluxos e sistemas orgânicos aparentemente despropositados ou resultado de acasos genéticos e imposição de forças externas, podem ser, em realidade, consequência de padrões complexos de organização. A natureza, pois então, teria inteligência assim com nós, como considera Bohm (BOHM; PEATS, 1989). Será que temos percebido a complexa dinâmica de (auto)-organização da vida? 
Cada parte de uma figura fractal é expressão de todo o fractal. A parte é um todo e o todo um conjunto de todos dele mesmo, como os hologramas. Dinâmicas que provocam a reflexão do quanto nos habituamos a pensar que estamos fora da natureza, que a mente está separada da matéria por razões causais e, portanto, não interfere na realidade dada, sendo a composição da vida na terra pode ser apenas uma soma mecânica de partes, uma colagem de peças como um mosaico.

Assevera David Bohm (1990) que, nas experiências físicas a que se submetia, verificou-se que o real dependia do físico que atuava sobre o experimento. Não que a realidade dependesse da mente humana para existir, segundo o autor seria uma perspectiva por demais antropocêntrica, mas a certeza de que a mente influi na matéria de alguma forma e que entre elas há relações interdependentes, interconexões, que não seguem razões causais. E mais, "em princípio, o universo inteiro determina cada uma de suas partes, o que é muito mais significativo do que na Física Clássica, na qual o efeito do universo pode ser desprezível e a forma da função entre as partículas é independente do todo" (BOHM, 1990, p. 196). Conquanto a ciência moderna se firme na separação mecânica entre partes isoladas e a aparente estabilidade da matéria, o mundo constitui-se por relações múltiplas indefinidas, orgânicas, fractais e caóticas, isso quer dizer, não-lineares, sendo a realidade, portanto, indivisível.

Nós, por vários motivos, deixamos de considerar a complexidade registrada em cada ínfima e imensa forma de vida e que nós vivemos no conjunto de muitas outras vidas. Desse modo, como superar a separação aparente entre nós e o mundo?

As relações estéticas possibilitam apreender o mundo sensivelmente, perceber em sua totalidade, no sentido de não fragmentá-lo. Pela intuição esse mesmo mundo pode ser visto de dentro, observando o que é diferente sem construir, para tanto, padrões estáticos e hierarquias de valores. Que o mundo não se centra no ser humano, embora tenhamos criado artificialmente esta impressão. Há muitas outras vidas igualmente importantes como a nossa e nós dependemos dessas vidas.

A implicação da psicologia nas questões "ecológicas" aqui levantadas não pode ser a de considerar a natureza, as demais formas de vida e o meio ambiente apenas como contexto do ser humano e/ ou como um conjunto de condições de possibilidades de um fenômeno ou evento ocorrer, mas de considerar que a vida humana na terra só é possível via a existência e permanência destas mesmas dimensões. Modificar os fundamentos sociais, científicos e econômicos que promoveram a concepção aparente de ruptura entre ser humano e natureza possibilitará a construção de outro e diferente projeto de sociedade, sustentada em outra ética-estética de vida.

"Quanto mais unificadamente diverso, dispersadamente atento, estiver, sentir, viver, for, Mais possuirei a existência total do universo, Mais completo serei pelo espaço inteiro fora" (PESSOA, 1983, p.117). As relações estéticas podem, assim sendo, potencializar a vida no mundo e em nós, favorecendo a quebra das lógicas formais, a irrupção das percepções, a decomposição e recomposição das formas e, no nosso ponto de vista, a criação de outras éticas de existência. 


\section{CONSIDERAÇÕes FinaIS}

A crítica às práticas científicas modernas faz-se pertinente enquanto uma crítica aos moldes de pensamento que perpetuam e fundamentam uma práxis humana em contextos outros, ou seja, a um projeto de sociedade que não se sustenta na manutenção da vida. Reconstruindo os paradigmas, debatendo sobre os princípios, podemos tecer pouco a pouco a teia das relações da vida e também entre psicologia, ser humano e natureza.

A experiência estética cunha rumos tortuosos, porém bem definidos para um novo horizonte de existência. Implica, igualmente, uma possibilidade de vivência complexa e integral e outra ética, pautada na sensibilidade e na intuição mais que na razão intelectual. Para a qual os movimentos importam tanto ou mais que os produtos, e na qual o tempo é tempo também de apreciar, contemplar, experimentar, ver, rever e imaginar.

As relações estéticas duplicam-se em si mesmas e se fazem infinitas como fractais nos quais se repetem as formas, mas produz forma outra: dinâmica e suntuosa por sua infinitude capacidade de se mostrar irreverente. Neste sentido, essas reflexões são de fundamental importância para a psicologia, pois sem entorno, sem contexto, sem ambiente ou natureza, o ser humano o que é? O que possui? Como inventa? Cabe a nós psicólogos e cientistas buscarmos alternativas para construir relações mais sensíveis com o mundo, a fim de preservar o mundo, bem como a nossa integridade.

Se as relações estéticas possuem relações estreitas com a arte, enfatizamos que também as teçamos com a vida, na vida, para que em cada movimento do que é vivo, sejamos pegos pela emoção surpreendente de estarmos olhando como pela primeira vez. Goethe já entedia em sua época que havia um grande paralelismo entre arte e natureza, cujos produtos de ambas independem da finalidade que o homem impõe a eles (KESTLER, 2006). Por isso pôde se perguntar pelas cores quando olhava as flores; sobre a finalidade das formas e metamorfoses quando observava a vida. Pena de uma época que entendeu que o que Goethe fazia não era ciência e não tinha validade.

Na certeza de que não nos é mesmo possível pensar o instável por meio do estável, o movente por meio do imóvel, o impermanente na permanência, o conjunto isolando suas partes, as ponderações apresentadas enveredaram pelas possibilidades das relações estéticas e experiências sensíveis, buscando aprender novas formas de perceber o todo organicamente vivo. 


\section{REFERÊNCIAS}

BACHELARD, G. A poética do espaço. São Paulo: Martins Fontes, 2008.

BAKHTIN, M. Estética da criação verbal. 4. ed. São Paulo: Martins Fontes, 2003.

BARRIOS, J. L. Cuerpo y percepción: subjetividad y escritura de la historia del arte. In: ENRIQUEZ, L. (Ed.). In (Disciplinas): estetica e histori del arte em el cruce de los discursos. Universidad Nacional Autônoma de México, p. 69-91,1999.

BERGSON, H. A evolução criadora. São Paulo: Martins Fontes, 2005.

BOHM D.; PEATS, F. D. Ciência, ordem e criatividade. Lisboa: Gradiva, 1989.

BOHM, D. O aparente e o oculto (entrevista). Revista Estudos Avançados, São Paulo, v. 4, n. 8, 1990.

CAPRA, F. O ponto de mutação. 28. ed. São Paulo: Cultrix, 2001.

CHARDIN, T. O fenômeno humano. São Paulo: Cultrix, 2008.

COELHO, J. G. Bergson: intuição e método intuitivo. Trans/Form/Ação, São Paulo, v. 21/22, p. 151-164, 1998/1999.

FOUCAULT, M. A arqueologia do saber. Petrópolis: Vozes, 1972.

JAPIASSU, H. Nascimento e morte das ciências humanas. 3. ed. Rio de Janeiro: Francisco Alves, 1983.

KESTLER, I. M. F.: Johann Wolfgang Von Goethe: arte e natureza, poesia e ciência. História, Ciências, Saúde - Manguinhos, v. 13 (Suplemento), p. 39-54, out. 2006.

MAFFESOLI, M. Elogio da razão sensivel. Petrópolis: Vozes, 1998.

MANDELBROT, B. Fractais: uma forma de arte à bem da ciência. In: PARENTE, A. (Org.). Imagem-máquina: a era das tecnologias do virtual. São Paulo: Editora 34, 2001. p. 195-200.

MATURANA, H. R.; VARELA, F. J. A árvore do conhecimento: as bases biológicas da compreensão humana. São Paulo: Pala Athenas, 2001.

MORIN, E. A inteligência da complexidade. São Paulo: Fundação Peirópolis, 2000 . 
PEIXOTO, N. B. O olhar estrangeiro. In: NOVAES, A. et al. O Olhar. São Paulo: Companhia das Letras, p. 361-366, 2003.

SANTOS, B. S. Um discurso sobre as ciências. São Paulo: Cortez, 2003.

SANTOS, B. S. Conhecimento prudente para uma vida decente: um discurso sobre as ciências revisitado. São Paulo: Cortez, 2004.

SANTOS, M. 1992: A redescoberta da natureza. Estudos Avançados, v. 6, n. 14, p. $95-106,1992$.

SAlATINO, A. Nós e as plantas: ontem e hoje. Revista Brasil. Bot., São Paulo, v. 24, n. 4, p. $483-490,2001$.

SPINOZA, B. Obras Completas: Ética III. São Paulo: Abril Cultural, 1979. Coleção Os Pensadores.

VÁSQUEZ, A. S. Convite à estética. Rio de Janeiro: Civilização Brasileira, 1999.

VYGOTSKY, L. S. Historia del dessarollo de las funciones psíquicas superiores. In:__ Obras escogidas III: problemas del desarrollo de da psique. Madrid: Visor, p. 11-46, 1995.

VYGOTSKY, L. S. Psicologia Pedagógica. São Paulo: Martins Fontes, 2001.

ZANELLA, A. V.; SAIS, A, P. Reflexões sobre o pesquisar em psicologia como processo de criação ético, estético e político. Análise Psicológica, v. 26, n. 4, p. 679-687, out. 2008.

Recebido em: maio de 2009

Aceito em: janeiro de 2011 